\title{
Repercussões da Violência na Construção da Identidade Feminina da Mulher Presa: Um Estudo de Caso
}

Repercussions of the violence in the feminine identity construction of the arrested woman: A case study

Vanessa Ponstinnicoff de Almeida

Universidade

Presbiteriana Mackenzie
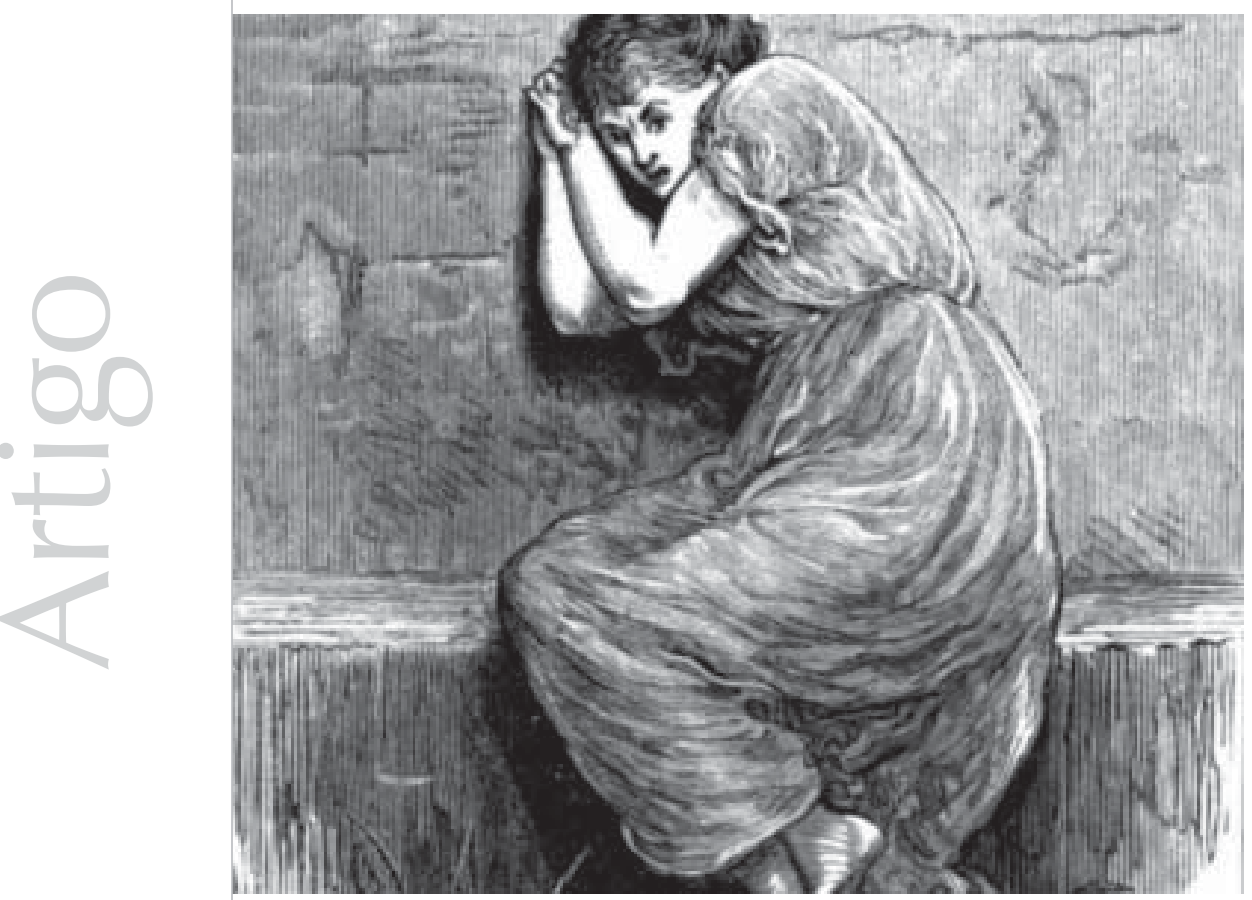


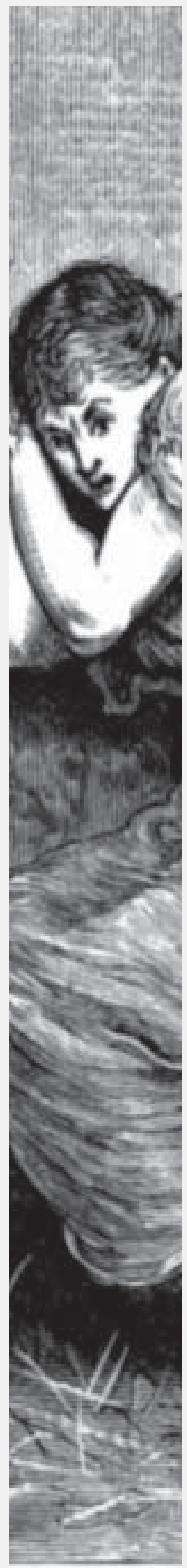

Resumo: $O$ presente trabalho procurou identificar a influência que os ciclos de violência exercem na formação da identidade da mulher presa. Além das implicações psicológicas, supôs-se que havia uma relação entre o padrão violento e a prática da criminalidade. Após o levantamento do referencial teórico, foram realizadas três entrevistas semi-dirigidas, gravadas, e posteriormente transcritas, com uma detenta que cumpre pena em regime semi-aberto, numa prisão no Estado de São Paulo. O material coletado foi analisado qualitativamente, o que facilitou uma compreensão não conclusiva dos motivos que levaram a colaboradora a agir de maneira criminosa, e, menos ainda, que apontasse saídas e soluções para suas dificuldades. Visou-se a um entendimento acerca da construção de sua identidade e de como o ciclo de agressões pudesse ter influenciado suas escolhas e atitudes. Durante a narrativa, a colaboradora destacou a violência em diversos momentos de sua vida: em casa, em seu meio social, com o parceiro e na prisão, bem como refletiu acerca das repercussões desse histórico. Nesse caso, verifica-se que a falta de recursos e de oportunidades de trabalho, a violência doméstica, a drogadição e a criminalidade, além de um filho de três anos, são apenas fragmentos de toda a formação de sua identidade. Ademais, percebe-se que ouvir o relato de vida de outra pessoa proporciona a revisão das próprias atitudes e atua na quebra de preconceitos, pois permite uma aproximação do ser humano enquanto possibilidade de eterna construção. Por fim, propõe-se a execução de estudos posteriores que possibilitem a elaboração de projetos com egressos bem como a criação de programas de intervenção psicológica no sistema prisional.

Palavras-chave: violência, identidade, criminalidade feminina, sistema prisional.

Abstract: The objective of the present paper is the identification of the influence that violence circles exercise in the arrested woman's identity formation. Besides the psychological implications, it was supposed that there was a relation between the violent standard and the crime practice. After identifying the theory reference, three recording half-directed interviews with an arrested woman who accomplishes penalty on the half-open police system in a São Paulo state prison were realized and then transcribed. The collected material was analyzed qualitatively, what made easier to come to inconclusive comprehension of the reasons that led the collaborator to get into the criminal way, and also that indicated the solutions to her difficulties. This paper aimed at the comprehension of the construction of her identity and the way the aggression circle could have influenced her choices and attitudes.During the narrative, the collaborator highlighted the violence in several moments of her life: at home, in her social relations, with her partner and in prison, and she also reflected about these historical repercussions. In this case, it was verified that the lack of resources and opportunities of work, the domestic violence, the drugs, criminality and a three-year-old son are only fragments of her identity formation. Besides it was perceived that listening to other people's relates of life gives way to our own attitudes' revision and it helps to eliminate prejudice, because it permits other people's approximation as a possibility of infinite construction. Finally, it was proposed the elaboration of subsequent studies, which could make possible the elaboration of projects with ex-prisoners as well as the creation of psychologist intervention programs in the prison system.

Key words: violence, identity, female criminality, prison system. 
"Como as mulheres vitimas de violência se percebem? Qual o valor que atribuem a si mesmas e a seus desejos e direitos? Qual a repercussão, na identidade dessas mulheres, dos recorrentes ciclos de violência em suas vidas?"
O presente trabalho partiu da intenção de relacionar assuntos considerados atraentes no âmbito pessoal e também relevantes no aspecto social. Nesse sentido, no decorrer da graduação, o contato com a fenomenologia vista como uma abordagem dos problemas filosóficos segundo um método que busca a volta às 'coisas mesmas', numa tentativa de reencontrar a verdade nos dados originários da experiência - permitiu a escolha do caráter metodológico considerado como a mais abrangente e explicativa metodologia de investigação do fenômeno estudado.

Além disso, parte do interesse sobre a área surgiu com as aulas de Psicologia jurídica, em que os direitos humanos e suas implicações no psiquismo puderam ser melhor esclarecidos, e também com as aulas de Psicologia comunitária, nas quais a violência doméstica foi apresentada e pôde-se perceber o quanto tais questões ainda não foram analisadas do ponto de vista das maiores interessadas, ou seja, das próprias mulheres. Partindo da reflexão de que algumas saídas podem ser encontradas por quem sofre a violência doméstica, chegou-se à indagação de que a criminalidade talvez pudesse ser uma delas, como forma de expressão de uma angústia ou mesmo de um comportamento familiar que se repete. Apesar disso, não se pode estabelecer uma relação causal entre a violência e a criminalidade. O que se pode supor é que a violência recorrente repercute de maneira decisiva na construção da identidade feminina.

Surgiram, então, as seguintes questões: "Como as mulheres vítimas de violência se percebem? Qual o valor que atribuem a si mesmas e a seus desejos e direitos? Qual a repercussão, na identidade dessas mulheres, dos recorrentes ciclos de violência em suas vidas?" Dessa forma, foi possível realizar a junção de diferentes temas: a auto-imagem, a construção da identidade, a violência e a possível reversão da posição de vítima (violentada) para a de culpada (presa).
O fato de a pesquisadora ser mulher por si só já exprime a intenção de explorar o universo feminino, tema central do trabalho, com toda sua complexidade e implicações do "existir" como mulher. Foi considerado imprescindível que o estudo envolvesse o resgate do feminino perdido em uma sociedade na qual a mulher não passa de uma "parceira sexual" do homem, alguém que cuida da família, é frágil, dependente e sentimental, para uma visão mais humanizada que considere inclusive a visão de si mesma na realidade em que vive. Inicialmente, a proposta de estudo estava voltada à violência direcionada ao próprio marido agressor, mantendo-se no tema da violência conjugal. Esperou-se, inicialmente, encontrar, entre as presidiárias, algumas colaboradoras que tivessem sido vítimas dessa violência e, ao invés de se manterem submissas a essa situação, a tivessem revertido e direcionado de maneira agressiva ao próprio marido, como se uma alteração em suas autoimagens possibilitasse a passagem do papel de vítimas para uma reação violenta. A relevância deste estudo residiria na percepção do processo de transformação do autoconceito dessas mulheres, a fim de interferir em situações semelhantes a tempo de revertê-las de forma positiva, como o término da união com o agressor em lugar de aceitar a repetição da violência.

Percebeu-se, assim, a dificuldade de coleta de dados desse tema junto a mulheres presas e optou-se por analisar as situações recorrentes de violência sofrida pelas mulheres desde a infância até a vida adulta. A delimitação do tema, por sua vez, relacionado às mulheres presidiárias, refere-se à hipótese de que haja uma relação entre a presença constante de violência em suas vidas e o fato de terem realizado atos criminosos, além do efeito desses atos no seu 'ser-no-mundo' e na construção de suas identidades.

Dessa forma, o objetivo principal na realização do trabalho foi o de compreender a trajetória 
de vida dessas mulheres e de como estas chegaram a praticar atos criminosos em suas vidas. Entre os aspectos estudados para fundamentar a compreensão, pode-se destacar: a Psicologia jurídica, no sentido de relacionar atos infratores a implicações psicológicas; a violência doméstica, que pode ser considerada como mais uma forma de repressão do feminino na sociedade; o método fenomenológico, que estuda o fenômeno 'pelos olhos de quem vê', além da influência do ser-no-mundo dessas mulheres em sua auto-imagem e a relação da sua construção de identidade com a situação da criminalidade atual.

Tratando-se de um estudo sobre a violência contra a mulher e suas implicações psicológicas, o tema já mostra sua relevância para a sociedade. Sendo assim, a percepção dos papéis sociais que a mulher possui na realidade brasileira é um dos aspectos a serem abordados. Nesse contexto, sabe-se que a violência doméstica apresenta índices preocupantes em todo o País, sobretudo quando se considera que a passividade diante de sua ocorrência implica inclusive a anuência ao desrespeito dos direitos fundamentais do ser humano. Dessa maneira, faz-se extremamente necessário o estudo sobre suas repercussões contra as mulheres em vários aspectos de sua vida.

A retomada do potencial feminino, que ocorreu com a liberação feminina e com a entrada da mulher no mercado de trabalho, promovendo a desconstrução das famílias de núcleo patriarcal, demonstram um novo interesse pelo que a mulher pode oferecer e a responsabilização pelo próprio destino. Partindo desse aspecto, pode-se estabelecer uma relação entre a identidade da mulher e a compreensão do porquê, apenas em 2004, a violência de gênero passou a ser considerada como um crime, pelo Código Penal, que exija pena de maior gravidade.
De acordo com Sobral (2002), a mulher agredida tem sua situação agravada pelo pacto de silêncio que reina em suas relações interpessoais, haja vista a estreita relação mantida entre a vítima e o algoz, que é sobretudo caracterizada pela assimetria do poder. Constantemente, a vítima, com receio de ser agredida e sofrer retaliações, se cala. Uma das possibilidades deste trabalho foi a identificação de alguns fatores que pudessem levar a essa repetição por suas vítimas potenciais (mulheres, foco do presente estudo, e crianças). Além disso, procurou-se encontrar a importância dessas questões (e de outras que porventura surgissem com o decorrer da pesquisa) para essa mulher em especial, a colaboradora, e identificar as possíveis soluções que ela própria considera significativas para esse problema, já que é ela a principal interessada no processo.

A integração da teoria encontrada com as percepções da entrevistada foi utilizada no processo de análise, a fim de realizar algumas considerações representativas sobre o fenômeno da violência recorrente, pois, como se não bastasse a presença específica da violência doméstica, de acordo com Sobral (2002), esta é considerada um assunto privado, e o que se passa dentro do 'lar' deve ser resolvido pela própria família. Apesar da interferência de terceiros ser vista como um desrespeito à intimidade da família, a violência doméstica afeta os direitos fundamentais do ser humano e atinge, de forma reflexa, a sociedade, posto que transcende os limites do âmbito familiar, afirmando-se, inclusive, que é lá que se inicia a violência urbana. Por isso, como um comentário adicional, faz-se extremamente necessária a implantação de uma política pública eficiente voltada para a busca de soluções para o problema, além de estudos desenvolvidos na área.

Assim sendo, o presente trabalho buscou, a partir do relato da história de vida de uma mulher presidiária, identificar aspectos do seu 
"ser-no-mundo" e repercussões de suas vivências cíclicas de violência na construção de sua identidade feminina.

Cabe o esclarecimento de que a análise realizada não deve ser percebida como um fim em si mesma, já que o relato da colaboradora, material primeiro das compreensões, possui o viés da dúvida (já que não há como comprovar o que está sendo dito pela mesma), do medo (em relação à utilização das informações fornecidas para a pesquisa), da imaginação (fantasias dessa mulher acerca das situações descritas e interpretações subjetivas a respeito de suas declarações) e do olhar da pesquisadora (que pressupunha encontrar determinados aspectos). Espera-se, portanto, que o leitor seja capaz de contextualizar as falas da entrevistada e de observar além do que está sendo dito, a fim de captar aspectos que se constituíram, logo depois, como objetos de análise final.

$\mathrm{Na}$ busca de realizar tais compreensões, propôs-se integrar aspectos diversos que pudessem auxiliar na identificação explicitada pelo problema central da pesquisa. Para tanto, tratou-se, ao longo deste trabalho, de questões relacionadas à violência, à sua percepção em alguns contextos e, mais especificamente, à violência doméstica e à realidade penal brasileira, além da pretensão de se fundamentar teoricamente o relato da colaboradora, diminuindo, dessa forma, as interpretações distorcidas de sua realidade.

Considerações a respeito da criminalidade feminina também foram estabelecidas, levando-se em conta seus papéis em relação ao crime, a fim de identificar possíveis fatores que pudessem estar relacionados à sua inclusão nesse sistema e a questões referentes ao gênero e à construção da identidade, bem como apontar algumas percepções acerca do "ser-no-mundo" dessa mulher.

A apresentação teórica original foi iniciada com um breve histórico do tratamento da mulher e de aspectos acerca da violência doméstica, que permitiu compreender a presença feminina nos principais períodos históricos. Além disso, explicitaram-se as significativas transformações sofridas em sua inclusão social e como esses fatores podem interferir na autoimagem das mulheres ao longo dos anos, tal como a interferência no tratamento que as mulheres recebem em seus lares atualmente. Para a apresentação do presente estudo, serão relatadas, a seguir, algumas reflexões acerca do depoimento da colaboradora, identificada pela primeira letra de seu nome: 'E.'

\section{Pensando o depoimento de uma mulher presa}

A execução deste tópico visou, principalmente, à localização de aspectos subjetivos na narrativa de uma colaboradora que tem, em sua construção de identidade, a presença recorrente da violência. Não se pretende, portanto, concluir os motivos que a levaram a agir de determinada maneira, e, menos ainda, apontar saídas e soluções para os seus problemas. Busca-se uma compreensão acerca da construção de sua identidade e de como as influências agressivas podem ter contribuído para isso. Para tanto, alguns fragmentos da história de vida contada por E. serão correlacionados aos fatores abordados neste estudo: violência doméstica e construção de identidade e criminalidade feminina, a fim de que se possa refletir a respeito da ocorrência e repercussão desta última, bem como as implicações que a violência causa, enquanto construto social, na vida da mulher presa.

E. é uma garota de 21 anos, residente de uma favela no Estado de São Paulo, e está cumprindo pena por roubo em regime semiaberto, devido ao bom comportamento na prisão. Tem um filho de 3 anos, fruto de um casamento que se iniciou e se desfez pela presença de violência. Trabalha em uma 
instituição que abriga funcionárias presidiárias e aguarda, atualmente, o resultado da solicitação de sua liberdade condicional. Essas são informações primordiais para que se possa entrar na história de violência relatada pela colaboradora.

A história de E. reflete um exemplo que pode ser comparado com a vida de muitas garotas, pois seus medos, desejos, sonhos, impedimentos e possibilidades poderiam fazer parte do relato de muitas jovens espalhadas pela periferia brasileira. A vida de E. constituise em mais uma afirmação da realidade que se apresenta progressiva e freqüente na sociedade atual, isso porque, de acordo com um estudo sobre o levantamento de dados do perfil da população carcerária feminina (Soares, 1999), constatou-se que as mulheres presas estão imersas em histórias de violência. Essa incidência foi e continua sendo um elemento constante na vida das mulheres presidiárias, tanto pelo ponto de vista da experiência individual quanto em relação aos parentes próximos.

Para exemplificar essa afirmativa: mais de 95\% foram vítimas de violência em alguma das seguintes situações: na infância, pelos responsáveis; na vida adulta, por parte dos maridos ou companheiros; quando foram presas por parte de policiais civis, militares ou federais. Ademais, $75 \%$ delas sofreu violência em pelo menos duas dessas situações, e 35\%, nas três circunstâncias. O estudo mencionado conclui que a maior parte das mulheres chega às prisões trazendo uma história prévia de maus tratos e/ou abuso de drogas. Isso não significa que tais experiências possam ser indutoras da criminalidade ou diretamente responsáveis pela entrada no sistema penal, pois certamente a maior parte das mulheres vítimas de agressão, assim como das dependentes de álcool e de outras drogas, está fora das cadeias ou penitenciárias.

Os dados mostram que a prisão, tanto pela privação de liberdade quanto pelos abusos que ocorrem em seu interior, constitui apenas mais um elo de uma cadeia de múltiplas violências que conformam a trajetória de uma parcela da população feminina. Nesse sentido, de acordo com Buglione (2000), no Brasil, a situação de vulnerabilidade das mulheres à agressão física e moral perpetuada por seus familiares, em especial maridos ou companheiros, é muito grave. Tradicionalmente tem-se a tendência de naturalizar a violência doméstica, o que supostamente legitima tratá-la como um problema exclusivamente de foro privado, gerando uma tácita aprovação ao fato e ao comportamento de banalização da sociedade em geral.

É importante inserir tais informações 'entre parênteses', com o intuito de localizar socialmente a construção da identidade de $\mathrm{E}$. Considerou-se que seu relato seria melhor compreendido na medida em que estivesse contextualizado, o que ampliou, dessa forma, a percepção das situações aqui apresentadas, bem como a das tentativas de compreensão das mesmas. Para o início das entrevistas, pretendeu-se mobilizar a colaboradora a buscar informações que ela considerasse relevantes em sua história de vida, fato que não seria possível com uma entrevista dirigida; portanto, contou-se com a sorte e com um suporte teórico indicado, que forneceu as bases e a possibilidade de acreditar que algum fator de violência se fizesse presente no relato de E. Os questionamentos foram orientados partindo da visão da colaboradora, o que caracterizou o processo deste trabalho como uma constante surpresa.

Como solicitado, a colaboradora iniciou seu relato descrevendo, de maneira geral, sua história de vida. Trouxe informações que englobam os fatores presentes no fato de haver crescido em um meio violento: apanhava da mãe, presenciava brigas na favela, apanhava de policiais na rua, do namorado, e, como se não bastasse, continuava a vivenciar
O estudo mencionado conclui que a maior parte das mulheres chega às prisões trazendo uma história prévia de maus tratos e/ou abuso de drogas. 
"...Como eu cresci na fovela (...), sempre vi muita violência (...) Qualquer coisa, neguinhojá saía arrastando o outro de madrugada (...), e eu, dentro de casa, só vendo, sem entender nada." essa repetição agressiva na prisão, ou seja, o histórico de violência fez-se presente em sua fala, desde o nosso primeiro encontro, caracterizando-se como uma situação recorrente na organização objetiva e subjetiva de sua vida.

E. relatou como período decisivo a sua adolescência. Levava uma vida que considerava como "supernormal, sabe? Escolatrabalho, trabalho-casa, casa-escola..." Tudo estável, até que conheceu um rapaz que ela caracterizou como um momento importante para que sua vida tomasse um rumo completamente diferente do programado: "Dei a maior cabeçada, larguei minha família, fui morar com um cara que só me afundou, me ensinou a fazer tudo de ruim..." E. acredita que, sozinha, não teria se envolvido com a criminalidade. Encantou-se pelo estilo de vida prometido pelo rapaz com o qual estava envolvida. "Por isso que, um pouco, eu tô aqui por causa dele, ele que me ensinou, né, senão eu não iria estar..." Muitas mulheres se vêem na mesma situação descrita por E., inserindose na criminalidade pelos próprios parceiros. A maioria delas atua constantemente como coadjuvante, mas E., como será posteriormente percebido, apenas se iniciou dessa forma. Cabe aqui uma questão: a violência de gênero antecede e acompanha a inserção da mulher no mundo da criminalidade?

O motivo de tal encantamento, de acordo com a própria entrevistada, encontra-se enraizado anos antes, em sua história familiar. "Na minha infância, eu sofri muito (...) porque eu não era uma filha revoltada e apanhava muito. (....) Da minha mãe... Por isso que eu não gostava dela (...). Uma revolta assim no coração, 'eu não posso tocar nela, que ela é minha mãe, não posso tocar nela..." E. afirma que não compreendia o comportamento violento da mãe, mas não se atrevia a questioná-lo (pelo menos, até então). No entanto, sentia que alimentava uma revolta em seu interior, que talvez estivesse esperando apenas uma oportunidade de se manifestar... "...Acho que apanhando, a gente se revolta mais ainda.. (...) Eu, que não sou revoltada e apanho assim, quero ver como é a vida de me revoltar. E me revoltei."

O relacionamento de $\mathrm{E}$. com o tal namorado iniciou-se quando ela estava com 17 anos. "Naquele tempo, a minha vida era toda organizadinha, tudo direitinho. (...) Só que aí, do nada, peguei ela assim, virei de cabeça pra baixo, sacudi assim, sabe? Dei uma reviravolta total na minha cabeça. Aí me envolvi com ele, minha mãe não gostava porque ele trabalhava no tráfico..." Sua mãe não gostava... Será que E. buscou um envolvimento que possibilitasse a vivência de novas emoções adolescentes, que afrontasse a autoridade incompreensível exercida pela mãe, ou tudo ocorreu apenas como uma simples coincidência? Frente à desaprovação materna ("Se você quiser ficar com esse vagabundo, você vai sair de casa"), E. opta, pela primeira vez, por um caminho que ela mesma encontrou: "Eu não deixei ela falar duas vezes."

A atitude impulsiva da adolescente que enfrenta a autoridade imposta pela figura da mãe tem suas bases em uma repetição de violência vivenciada desde a infância. "...Como eu cresci na favela (...), sempre vi muita violência (...) Qualquer coisa, neguinho já saía arrastando o outro de madrugada (...), e eu, dentro de casa, só vendo, sem entender nada." Encontra-se, logo depois, com o arrependimento em relação à atitude tomada. E. afirma, com um visível pesar: "Pior burrada que eu fiz no mundo!" É nesse fato que podemos constatar seus primeiros passos no universo da criminalidade. "Comecei a fumar maconha, de tudo um pouco, experimentei de tudo. (...) Aprendi a roubar em mercado, teve uma época que eu tava roubando em shopping, em loja, fazendo saque, fazendo umas coisas maiores... Aí, daqui a pouco, eu já estava envolvida no tráfico (de drogas)." 
A progressão no crime, ao mesmo tempo em que a afastava da família, afastava-a de si mesma. Sua auto-imagem via-se comprometida. "Teve um tempo na nossa vida que, sabe, eu olhei pro espelho, assim, pra mim mesma, magra, feia... Mó bonita eu era, nova... (...) não era mais eu! Não era, eu tava transformada..." Foram tantos e tamanhos os acontecimentos que, além de modificar sua realidade externa, sua identidade também não era mais a mesma. De acordo com Ciampa (2001, p.34), "é o sentido da atividade social que metamorfoseia o real e cada uma das pessoas." E. conta que considerava sua atividade ilegal, destrutiva para si mesma. De 'boa filha', passa a assumir o papel de adolescente revoltada, usuária e traficante de drogas. Não se reconhece mais. Seu próprio nome não é mencionado em parte alguma da entrevista. 'Pretinha' era o apelido que a caracterizava enquanto menina-mulher e que a fazia manter-se, mesmo que presa e distante da família, como parte integrante de sua identidade original. O estigma e a deterioração da identidade se fazem presentes a todo momento.

Apesar dessa manifestação de desaprovação com as conseqüências de seu relacionamento amoroso, E. considera que tinham uma relação "até boa" com o ex-marido. Porém, em seguida, menciona: "Ele nunca me bateu, nem nada (...), mas teve um dia que ele foi, não sei porquê (...) e me deu uma cabeçada assim (...) nossa, eu fiquei revoltada." E. sente-se ameaçada e envergonhada pela atitude do próprio marido ("meu pai tinha o maior respeito por ele"); tenta pedir socorro ("que raiva! (...) comecei a gritar"), mas logo percebe que se tratava de uma prática comum em seu meio, quando o pai, que, segundo ela, deveria agir em seu favor, apresenta-se como porta-voz da banalização da violência sofrida: "Não é nada, não, Pretinha, não é nada, não... 'vai' dormir vocês dois."

A consideração paterna de que E. deveria ignorar o que estava acontecendo e perpetuar o pacto de silêncio, apesar de incompreendida, foi inicialmente acatada: "Depois disso, eu continuei com ele." O mesmo motivo que a levou a fugir de casa repetia-se em sua vida. Apanhava da mãe, e agora, apanha do marido. Não pôde agir, pois antes estava sob uma 'ética universal' de proteção à figura de amor e respeito que a mãe deveria representar; agora, está sob a conivência paterna com seu agressor. As conservas culturais parecem cristalizar as relações de gênero.

Tempos depois, a violência tenta manifestarse mais uma vez: "Passou um tempo e ele veio querer levantar a mão pra mim de novo (...); depois do dia que ele levantou a mão, já era, acabou." Negando as condições que a circundavam, E. tentou impedir que esse ciclo se mantivesse contra ela. Com a mesma impulsividade que a levou a sair da casa dos pais, separou-se do marido, abandonou o tráfico e o uso de drogas, voltou para a casa da família com o filho nos braços e tentou assumir um novo papel. "Depois que eu me separei dele, eu vi realmente a liberdade." Não precisava mais dar satisfações ao marido, aos pais; era dona de seu próprio destino. Encontrou outros namorados ("nada sério, porque eu falei pra mim mesma: eu não gosto de mais ninguém") e fez as pazes com a mãe, fato essencial que a fez abandonar as lembranças de tudo o que havia acontecido entre ambas até então. "Eu comecei a amar tanto a minha mãe, tanto, tanto... (...) Todos os anos que eu passei achando que ela não gostava de mim, em meses, foi tudo de bom." Porém, logo em seguida, um fato repentino vem para novamente abalar tudo o que $\mathrm{E}$. estava construindo: a morte da mãe. Além da surpresa e do medo de que o arrependimento não se fizesse a tempo, a família começa a passar falta de bens em casa, e E. sente-se na obrigação, como filha mais velha, de tomar para si a responsabilidade de suprir as necessidades que começavam a surgir. Retoma seus contatos profissionais e chega a implorar 
por um emprego, posicionando-se como uma espécie de vítima da ameaça social: “Eu preciso de um trabalho, senão vou fazer coisa errada, me ajuda..." Depara-se com 'oportunidades fáceis' de obtenção de dinheiro, mas recusa-se, e assume o risco: "Eu quero o meu dinheiro. O que é meu. Pra falar que, independente de tudo, eu suei pra ter." É retomado o ciclo.

O envolvimento com o crime se configura como uma alternativa financeira que vem no intuito de atender às buscas de $\mathrm{E}$. de uma forma já conhecida, já iniciada. Nem mesmo o assassinato do ex-marido, através de uma briga decorrente do tráfico, é capaz de abalar a convicção de que essa era a sua saída. Por que tanta persistência? Porque E. tinha um projeto, e era a fim de concretizá-lo que ela haveria de passar por tudo de novo; foi em prol de um bem maior, o bem-estar da família, que E. afirma ter abdicado da própria liberdade. "Tudo o que eu faço é se precisar. (...) Porque eu jamais quero ver a minha família precisando." Ciampa (2001) afirma que a realidade é uma possibilidade já realizada. $\mathrm{E}$. conhecia sua realidade. E conhecia um modo de agir sobre ela.

Durante a participação em um roubo de carro, E. se deparou com as conseqüências do risco que aceitara assumir: a chegada da polícia. "Na contramão, descendo aquele monte de viatura, já comecei a entrar em desespero. (...) Vem tudo e mais um pouco na sua mente na hora, você quer pular do carro, correndo de qualquer jeito." E as promessas do crime ("Não esquenta, que eu vou segurar tudo. (...) Você vai embora para cuidar do seu filho") começam a se desfazer; enquanto apanhava da polícia, sentiu um tiro passar de raspão pela sua orelha e percebeu a insignificância a que a tinham reduzido: "E se eu fosse inocente, mesmo?" Próxima etapa na construção subjetiva de E.: a entrada na prisão.

Fortalecendo a circularidade dos fatos de sua história de vida, E. sentiu que, mesmo (e talvez principalmente) na prisão, os comportamentos violentos continuariam sendo a tópica que orientaria suas atitudes e pensamentos. "Qualquer coisa, por mínimas coisas, o povo já quer dar paulada, facada, pedrada. (...) Eu não gosto de brigar, eu não gosto de violência com ninguém." Porém, para adaptar-se e integrar-se à nova realidade, $\mathrm{E}$. encontra alternativas para manter-se dentro do universo da violência prisional: "É lógico que, se alguém for querer tirar a minha vida, vou tirar a da pessoa antes da pessoa tirar a minha. (...) Mas sou contra a violência, sou da paz." Uma confusão de papéis que envolve moral $X$ sobrevivência instaura-se em sua realidade. E. precisa ser alguém reformulando a si própria. "Re-atualizamos, através de rituais sociais (prisão), uma identidade pressuposta (criminosa), que assim é vista como algo dado" (Ciampa, 2001, p.163). E. interioriza a personagem que lhe foi atribuída, identificase com ela. Não teria sido esse ímpeto na busca de ser alguém que a moveu durante todo o processo? Por que isso não aconteceria na prisão também?

Dentro desse novo universo de possibilidades limitadas, a identidade feminina de E. alterase, ganha força, e apresenta-se em sua vida como uma crescente transformação que a aproxima dos papéis até então considerados predominantemente masculinos, inclusive no que concerne à violência e criminalidade, fato esse discordante do observado em referenciais teóricos utilizados, segundo os quais a mulher apenas realizaria os chamados 'delitos de gênero' ou atuaria como auxiliar em crimes maiores, praticados por homens de seu convívio. Na nova visão de mundo de E., a mulher passa a penetrar territórios novos, a aceitar novos desafios, a vivenciar situações consideradas masculinas. "Porque eu acho que o que um homem é capaz de fazer, uma mulher também é."

Apesar da busca por igualdade de direitos, E. desconcertou-se ao constatar que a 
aproximação de papéis traz consigo uma igualdade também de deveres e responsabilizações. Afirma que, durante as revistas policiais que ocorriam na favela onde morava, "podia ser mulher, o que fosse, apanhava igualzinho os 'home'..." Uma igualdade diferente. E. parece camuflar uma incompreensão que se manifesta em suas falas através de indignações em relação ao tratamento sofrido por mulheres que vivenciam situações parecidas com a sua. "Não tinha um pingo de respeito em falar assim: 'não, ela é mulher, né meu?' Era normal, como se fosse homem..." Além disso, passa a considerar "normal (a) polícia agredir uma mulher, 'tando' numa boca de madrugada", dada a freqüência com que essa situação se repetia. A mesmice do mundo se repete na mesmice de sua vida. O sentimento de injustiça surge nas entrelinhas de uma tentativa de localização dos papéis femininos que, em sua vida, não foram muito bem sucedidos: sua identificação com a mãe ocorreu apenas nos momentos finais de vida da mesma; sua realização como esposa the trouxe muitos prejuízos e sofrimento, e sua tentativa de prover uma vida melhor para o filho terminou por levá-la de volta à criminalidade. Confirmando a hipótese de Buglione (2000) acerca da desvalorização da mulher enquanto identidade do feminino, E. desenvolve o desejo de ocupar novas posições, um status maior para sua vida e busca conquistar para si um local masculino por excelência: idealiza a criação de uma oficina mecânica. "Porque mulher pode tudo (...). Então, eu vou montar logo uma oficina bem grande, bem chique, né? Movida só de mulheres. (...) E fazer uma profissão que é coisa de homem." Apesar de tatear um novo território, E. não abre mão de manter-se em sua individualidade feminina, mesmo que sutilmente. "Eu quero ver aquele monte de mulher naqueles 'macacão', nada daqueles 'macacão' largo, tudo apertadinho, bonitinho, sabe?"

Ainda em relação à identidade feminina, E. nos fala sobre a provação constante pela qual passam as mulheres que tentam assumir suas potencialidades frente à predominância masculina. "O homem sempre vai 'tar' falando: 'não, você não é boa o suficiente que nem eu sou'. E ela vai 'tar' batendo o pé e falando: 'lógico que eu sou, lógico que eu sou'." A historicidade da submissão feminina ecoa na subjetividade de E., que sente, a cada instante, a necessidade de contrariá-la e demonstrar que pode superá-la.

Além disso, o fato de haver ingressado no universo do crime parece ter atuado no sentido de que E. reformulasse toda sua visão acerca das possibilidades dessa realização. Pode-se dizer que sua identidade está sendo fixada no papel de presidiária, que E. ainda vive e acredita que demarcará sua vida por muito tempo depois de sua saída da prisão. Afirma que, quando sair da cadeia, "ninguém vai querer me dar trabalho (...), vai olhar na minha carteira, tá lá marcado: 'ex-presidiária'"... Mesmo sendo 'ex', o peso do 'presidiária' ainda é muito forte, inclusive no que diz respeito a relacionamentos afetivos. E. considera que não pode se envolver com quem ela crê que não faça parte de sua realidade. Sobre um namorado recente, estagiário na instituição onde E. trabalha, ela diz: "Eu falo pra ele: 'meu, seu mundo é um, meu mundo é outro, não tem nada a ver'. (...) Eu falo pra ele que o nosso mundo é diferente." E. tenta se afastar, deixando de assumir uma identidade que the foi, de acordo com Ciampa (2001), socialmente negada: envolver-se com alguém que não pertence à mesma realidade que ela. De acordo com o autor, as posições que se pode ocupar e as relações que se pode manter dependem da identidade. Enquanto presidiária, E. reluta em assumir um compromisso com um rapaz que está "no mundo aqui fora."

Durante a progressão das entrevistas, foi possível notar o quanto E. foi se apropriando das informações que trazia a respeito de si mesma. Alternava situações de esperança,
"Eu falo pra ele: 'meu, seu mundo é um, meu mundo é outro, não tem nada a ver'. (...) Eu falo pra ele que o nosso mundo é diferente." 
expectativas em relação a seu futuro e um grande medo de não saber como agir quando não estiver mais sendo controlada por uma instituição total que molda sua maneira de ser-no-mundo, além de marcar um processo de estigmatização e deterioração da identidade. Falou de planos como se fossem algo inatingível, apesar de apoiar-se em sua possibilidade de concretização como uma forma de 'salvação'. Todavia, não acreditava que seria capaz de alcançá-la. Distinguia claramente seus desejos de suas possibilidades de concretização. Dizia: "Quero terminar de estudar, até fazer uma faculdade, quem sabe? (...) Quero ser alguém na minha vida. Dar um exemplo pro meu filho", ao mesmo tempo em que afirmava: "Eu não sei se saio hoje, amanhã volto pra essa vida, porque se eu não tiver oportunidade, eu vou voltar." Ciampa (2001, p.200) acredita que, "de um lado, o homem é ser-posto; do outro, é vira-ser." E. possui os diferentes caminhos abrindo-se à sua frente. A escolha de qual seguir dependerá da integração que a colaboradora realizará a respeito de como já foi, de como se encontra hoje em dia e de como espera ser no futuro. Infelizmente, sua insegurança possui bases em um aspecto estatístico da realidade brasileira. De acordo com Pedroso (2002), a falta de oportunidades aos egressos do sistema prisional, decorrente, muitas vezes, do preconceito, constitui uma das maiores causas de reincidência criminal. Esse foi, inclusive, um aspecto manifestado por E. que levou à sugestão de futuros estudos relacionados ao tema, de programas que permitam a manutenção de emprego aos egressos do sistema prisional.

No momento das entrevistas, E. transferia a responsabilidade sobre suas atitudes a fatores externos, retirando-as de si própria. "Tenho o maior sonho de que quando eu sair, Deus vai abrir uma porta pra mim só de coisas boas, pra poder fazer tudo o que é certo, pra 'mim' não ter que correr atrás de tudo o que é errado de novo." Orienta inclusive sua vivência prisional como sendo algo decorrente de uma situação na qual se encontrou sem perspectivas, agindo sempre a favor de outros, anulando-se. "Eu sou uma menina carente (...), sempre me sinto muito sozinha. (...) Por isso que eu vivo só em intenção deles (família), eu... Eu sou independente. Tudo o que eu faço é por eles, quero ser alguém na vida pra dar um orgulho pra eles."

A importância dada à família encontra reforçadores no momento de sua prisão. "Amigo? Amigo é a minha família. Fora eles, não tenho." Sente-se abandonada pelo grupo de iguais, que, segundo E., "nem um pedacinho de papel escrito 'e aí, você 'tá' bem?'" enviam para confortá-la. A solidão mencionada reflete a insegurança que a colaboradora manifesta em seu relato sobre a vida na prisão. "Será que alguém vai vir me ver? Será que alguém vai lembrar de mim?" $\mathrm{O}$ medo de ser esquecida permeia as falas de E. acerca de seu ingresso na cadeia. Ciampa (2001) auxilia a compreender esse movimento como uma adaptação natural. De acordo com o autor, a realidade deve ser socialmente compartilhada, para que seja possível a significação do que ocorre. Quando se vê abandonada pelos amigos e acolhida pela família, E. sente a necessidade de reintegrar-se a esse grupo do qual havia, mesmo que temporariamente, se afastado, fortalecendo cada vez mais seus laços com o mesmo e reencontrando seu antigo (porém reformulado) lugar.

A proximidade da época de saída da prisão apresenta-se para E. como sua 'nova chance': tudo pode dar certo, ao mesmo tempo em que tudo também pode dar errado. É nessa ambigüidade, dependente, em grande parte, 
de sua própria capacidade, que reside a insegurança sentida pela entrevistada. "Eu não sei o que vai ser da minha vida quando eu sair daqui. Às vezes, eu mesma tenho medo de sair. (...) E parece que quando tá chegando o final, todo mundo vem querer 'botar' um obstáculo a mais na sua vida, pra ver se você volta pra trás de novo... (...) Eu não sei meu amanhã."

Ciampa (2001, pp.198-199) afirma que "a concretude da identidade é a sua temporalidade: passado, presente e futuro. Aparentemente, então, a dificuldade maior para o conhecimento da identidade estaria no futuro, que, por definição, hoje não é conhecido." O grande medo manifesto por E. é a possibilidade de repetição dos comportamentos de criminalidade com os quais ela já se identificou. "Quando eu sinto que tô indo embora, falo pra Deus: 'Ai, prepara o caminho pra mim porque eu tenho muito medo, muito medo mesmo de sair e fazer tudo de novo'. (...) eu vou ter que ter muita força mesmo, pra ir muito devagar e não querer tudo de uma vez, entendeu? (...) Porque querendo ou não, depois que a gente entra pra vida do crime, nunca mais sua vida é a mesma." E. traz à tona, nesse momento, o 'vício' provocado pelas facilidades do crime, mesmo que para isso seja necessário estar preparado para suas conseqüências.

Percebe-se, assim, que a colaboradora também pondera as repercussões negativas que a prisão trouxe para sua vida. "Nada compensa, nada compensa estar lá dentro, nada. (...) Porque lá é outro mundo, totalmente fora do normal daqui." Dessa forma, ao mesmo tempo em que manifesta a insatisfação com seu estado atual, ela mesma encontra a resposta para seu posicionamento em relação à criminalidade: constituir-se como um exemplo para o filho e para os irmãos menores, já que estes últimos estão iniciando um "flerte" com o mundo do crime: "... Eu quero sair, mudar, ser alguém, pra eles falarem: 'Olha, meu, sofreu bastante lá dentro e 'tá' aí, sendo a maior guerreira, 'tá' fazendo de tudo pra não ter que voltar de novo.'" Tenta configurar a prisão como um local ruim, incentivando sua família, a partir de sua vivência pessoal, a não se envolver com a criminalidade. Ao mesmo tempo, busca firmar-se como alguém forte, que conseguiu suportar as adversidades sofridas e conquistar seu próprio espaço.

Uma vivência interessante ocorrida com E. durante o período em que conversamos para a coleta de dados da entrevista foi o seu encontro acidental com um rapaz, em uma praça pública próxima a seu local de trabalho, em seu horário de almoço. Em relação a ele, E. observa: "Sabe qual é a vantagem de já ter sido louca um dia? É que um louco conhece o outro louco à distância." A identificação entre eles levou a uma conversa, na qual surgiram temas como o uso de drogas, oportunidades de vida, trabalho e liberdade. A troca de experiências entre ambos foi inevitável. Ouvindo o relato de seu 'companheiro', E. pôde perceber alguns aspectos de sua vida e compará-los aos do rapaz, chegando, inclusive, a aconselhá-lo: "Dá um pouquinho de valor pra sua vida, que você não tem filho, não tem mulher, não tem nada... (...) como você reclama de barriga cheia."

Ouve, também, o conselho fornecido por ele em relação à criminalidade: "Pô, eu sei que eu não sou ninguém, mas não faz mais isso, não." Quando questionada a respeito da repercussão dessa conversa, E. conclui: "Foi legal, me senti bem. (...) Eu não sou muito acostumada a dar conselho pra ninguém. Acho que eu tô mais acostumada a ouvir conselhos." 
"...Não vou culpar a sociedade porque eu não consegui trabalho num momento que eu 'tava' precisando e fui fazer coisa errada. A culpa foi minha. Mas (...) é uma culpa que não me pesa tanto na minha cabeça, porque tudo o que eu fiz foi pela minha família!"
Falar sobre sua história de vida e constatar que a mesma pode auxiliar alguém possibilitou para E. uma troca de papéis (com seu pai, sua mãe e com todas as figuras que a orientaram desde que se iniciou em sua experimentação de revolta), desencadeando, logo em seguida, um insight sobre sua posição atual: "...Não vou culpar a sociedade porque eu não consegui trabalho num momento que eu 'tava' precisando e fui fazer coisa errada. A culpa foi minha. Mas (...) é uma culpa que não me pesa tanto na minha cabeça, porque tudo o que eu fiz foi pela minha família!" Pela primeira vez, desde o início das entrevistas, E. se apropria de sua realidade. Apesar de identificar a interferência de fatores externos, considerase como atuante em sua história, não mais apenas como vítima ou incapaz de concretizar suas escolhas. Realiza-se, nesse momento, uma tomada de consciência em relação a si própria. Inicia-se um novo processo de transformação de sua identidade. "À medida que vão ocorrendo transformações na identidade, concomitantemente ocorrem transformações na consciência" (Ciampa, 2001, p.186). Dessa forma, como numa tomada súbita de elucidação, E. conclui sua narrativa, afirmando: "Mas tá bom... é vivendo e aprendendo, caindo e levantando... E vamos que vamos."

\section{Considerações finais}

Pode-se afirmar que a execução do presente estudo foi de extrema importância para o futuro exercício da profissão de psicóloga, isso porque, além do levantamento bibliográfico dos temas relevantes para a construção teórica do estudo, a experiência de ter entrado em contato com a história de vida de uma mulher em regime semi-aberto foi fundamental para o entendimento da visão fenomenológica. Antes das entrevistas, havia a restrição das palavras e considerações dos textos; depois delas, foi possível observar que o relato de vida e a visão que a pessoa tem da própria história vão muito além de qualquer produção literária. Uma contribuição extra ao envolvimento no estudo foi o fato de ter assistido a uma peça de teatro (Muros, de Jorge Spíndola, inspirada no conto O Muro, de Jean-Paul Sartre) que tratava da vida prisional. Seus atores, em grande parte, já haviam passado pessoalmente pela experiência da vida na prisão, e o contato com esse universo, mesmo que através de uma simulação, possibilitou compreender melhor e aproximar-se da realidade presente no relato da colaboradora.

Durante as entrevistas, E. pareceu ser uma adolescente, apesar de demonstrar ter muita história para contar. $\mathrm{O}$ fato de ter vinte e um anos, a mesma idade da pesquisadora, tornou a investigação ainda mais (pessoalmente) interessante, isso porque foi possível observar que a visão que as pessoas têm da vida está diretamente ligada às situações e fenômenos pelos quais passa. Um histórico de falta de recursos e de oportunidades de trabalho, violência doméstica, envolvimento com drogas e o mundo do crime, além de um filho de três anos, são apenas pedaços de toda uma construção histórico-pessoal. Nesse sentido, ouvir o relato da história de vida de outra pessoa indubitavelmente proporciona a revisão das próprias atitudes e atua na quebra de preconceitos, pois aproxima-nos do humano enquanto possibilidade de eterna construção.

Outro fator indispensável foi o envolvimento de E. durante as entrevistas, pois a mesma correspondeu com a sua vontade de se expressar e dividir suas experiências, o que contribuiu imensamente para a execução deste estudo. Além disso, mostrou-se 
interessada em obter um retorno acerca da compreensão realizada pela pesquisadora, posicionando-se com grande disposição de compreender e de aceitar novas formas de elucidação sobre si mesma. Assim como E., a instituição na qual o estudo foi realizado também facilitou intensamente a consecução do trabalho, na medida em que atendeu prontamente à pesquisa, abriu as portas para a 'observação', disponibilizou local para as entrevistas e permitiu a participação de uma de suas funcionárias.

Também no intuito de possibilitar a ampliação da relevância social deste estudo, baseandose nas falas da entrevistada, sugere-se a necessidade da proposição de estudos posteriores a este, que possibilitem a elaboração de um projeto relacionado à continuidade do trabalho de egressos do sistema prisional. E. referiu-se, como principal angústia referente à sua saída da prisão, à falta de emprego que possivelmente ocorreria devido a uma organização social falha e preconceituosa. Apesar de não verbalizar claramente, sabe-se que essa fala envolve também a identificação com papéis socialmente marginais e o sentimento de incapacidade decorrente da situação de aprisionamento.

A existência de projetos com egressos atualmente age apenas enquanto processo de desligamento do sistema prisional, ou como cursos de profissionalização. Nota-se a necessidade, porém, de uma continuidade desses empregos por algum período extra além do tempo de internação ou de tais cursos oferecerem uma bolsa a seus freqüentadores mais assíduos, a fim de que a readaptação social possa ser elaborada de maneira gradual e satisfatória. Tal fato poderia, inclusive, reduzir a reincidência criminal, na medida em que traria as tão mencionadas 'oportunidades', os benefícios ao desenvolvimento humano e, em conseqüência, ao desenvolvimento social.

Além disso, cabe aqui um comentário acerca da extrema necessidade de projetos, no interior do sistema penal, que desenvolvam aspectos psicológicos relacionados ao crime e, mais que isso, ao sujeito que o pratica. A realização de práticas grupais pode ser de extrema eficácia para a minimização dos efeitos decorrentes do internamento prisional e de sua interferência ao grupo social maior nos quais esses indivíduos se inserem. Dessa forma, observa-se a importância da formação pessoal do presidiário, enquanto sujeito privado de sua liberdade, mesmo que esta se dê no interior da prisão. Acredita-se que o investimento em construções estruturais desempenhadas pela escola, pela cultura e pela educação social possa ser capaz de produzir resultados surpreendentes.

Em suma, pode-se dizer que os objetivos iniciais deste trabalho foram atingidos, isso porque, partindo da visão inicial de que a violência sofrida pelas mulheres é um fato recorrente em suas vidas, bem como a repercussão negativa que isso tem em sua auto-imagem, foi possível ir além. A postura fenomenológica utilizada, ou seja, a busca da volta às 'coisas mesmas' e a compreensão do fenômeno pelos olhos de quem o vê possibilitou uma ampliação do olhar acerca da complexidade que envolve o tema e o que sua ocorrência causa na vida psíquica dessas mulheres. Através das três entrevistas realizadas, foi possível identificar aspectos das hipóteses iniciais, de repetição de um padrão violento no cotidiano das mulheres bem como de sua banalização, mas, sobretudo, a singularidade que esse fato demonstra na visão de quem o vivencia. 
A hipótese inicial de que a violência é um fenômeno recorrente na vida da mulher presidiária e influi na constituição de sua subjetividade se confirmou. Além disso, foi possível perceber que existem inúmeros outros fatores que repercutem positiva ou negativamente na vida das pessoas, influenciando naquilo que elas são e no que se tornarão. Isso quer dizer que, em vez de se restringir à violência recorrente na vida das mulheres e na implicação desse fato na construção de sua identidade enquanto encarcerada, constatou-se que o mesmo pode estar presente em sua constituição enquanto mulher. Parafraseando Cecília Meireles" : "E, nesse abismo do meu sonho, alheia a todo outro desejo, me decomponho e recomponho." Editora Record/Altaya. 
Vanessa Ponstinnicoff de Almeida

Psicóloga

Universidade Presbiteriana Mackenzie

Rua Vicência Faria Verssagi, 243 - Jd. Emília Sorocaba/ SP -

CEP.: 18031-080.Tel.: (15) 3233-3809 (15) 9133-1073

(11) 3331-8830 (11) 9224-4317

E-mail: vanessa_ponst@hotmail.com

Recebido 21/12/05 Reformulado 11/10/06 Aprovado 28/11/06

ANDRADE, V.R.P. A Violência contra a Mulher e o Controle Penal. In: Revista da Faculdade de Direito da UFSC, vol. 1, 1998, p. 207.

BUENO, S. Silveira Bueno. Minidicionário da Língua Portuguesa. Ed. rev. e atual. São Paulo: FTD, 2000.

BUGLIONE, Samantha. A Mulher enquanto Metáfora do Direito Penal. Jus Navigandi, Teresina, a. 4, no 38, jan. 2000, p. 1-2

CARDOSO, H. A. Globalização dos Direitos Humanos e dos Cidadãos. In: Juris Síntese, São Paulo, no 31, set/out, 2001, p. 1-27

CERVO, A. L. \& BERVIAN, A. Metodologia Científica. 5a ed. São Paulo: Prentice Hall, 2002.

CIAMPA, A. C. A Estória do Severino e a História da Severina. São Paulo: Brasiliense, 2001.

DEMANTO, C. (et al.). Código Penal Comentado. 5a ed. atual. e ampliada. Rio de Janeiro: Renovar, 2000.

DONICCI, V.L. A Criminalidade no Brasil (Meio Milênio de Repressão). Rio de Janeiro: Ed. Forense, 1984.

D'URSO, L. F. B. Proposta de uma Nova Política Criminal e Penitenciária para o Brasil. In: Síntese de Direito Penal e Processual, Porto Alegre, no 5, dez/jan, 2001, p. 52.

. Penas Alternativas. In: Síntese de Direito Penal

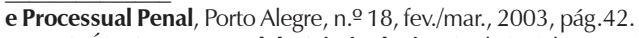
FARIAS JÚNIOR, J. Manual de Criminologia. $3^{\mathfrak{a}}$ ed. Curitiba: Juruá, 2002

FRANCO, A.S. (et al.). Código Penal e sua Interpretação Jurisprudencial. Pref. Paulo José da Costa Jr. 5ae ed. ren. e ampl. São Paulo: Editora Revista dos Tribunais, 1995

GIRARD, R. A Violência e o Sagrado. Trad. Martha Conceição Gambini. Rev. téc. Edgard de Assis Carvalho. São Paulo: Editora Universidade Estadual Paulista, 1990

GOFFMAN, E. A Representação do Eu na Vida Cotidiana. Trad. de Maria Célia Santos Raposo. 8ª ed. Petrópolis: Vozes, 1985.
Estigma - Notas sobre a Manipulação da Identidade Deteriorada. Trad. de Márcia Bandeira de Mello Leite Nunes. 4⿳亠丷a ed. Rio de Janeiro: Editora Guanabara Koogan S.A., 1988.

LANE, S.T. (org.) Psicologia Social - O Homem em Movimento. São Paulo: Editora Brasiliense, 1984.

MICHAUD, Y. A Violência. Trad. L. Garcia. São Paulo: Editora Ática, 1989.

NEOTTI, A. A Mulher no Mundo em Conflito. Ponta Grossa: Universidade Federal de Ponta Grossa. 1973.

PEDROSO, R. C. Violência e Cidadania no Brasil- 500 anos de Exclusão. São Paulo: Ed. Ática, 2002.

REIS, M.M.F. Análise da Construção Histórica da Imagem da Mulher como um Produto com Data de Validade e da Versão Contemporânea desse Fenômeno no Contexto Social Brasileiro. Dissertação de Mestrado apresentada na Universidade Presbiteriana Mackenzie. Orientação: Sérgio Bairon. São Paulo, 2000.

SAFIOTTI, H.I.B. A Mulher na Sociedade de Classes - Mito e Realidade. São Paulo: Editora Quatro Artes, 1969.

SCHULTZ, D. P. eSCULTZ, E. S. Teorias da Personalidade. Trad. Eliane Kanner. Rev. téc. Maria Helena Leal de Barros Berkers. São Paulo: Pioneira Thomson, 2004

SOARES, B.M. Prisioneiras: Vida e Violência atrás das Grades. Rio de Janeiro: Gramond/ CESec, 2002.

SOBRAL, K. M. A Punição Corporal Doméstica de Adolescentes: Aspectos do Direito Interno e do Direito Estrangeiro. In: Síntese de Direito Penal e Processual Penal, no. 12, fev.- mar./ 2002, p. 149.

SOUZA, I. M. C. C. De Causa e Efeito. In: Revista Brasileira de Direito de Família, no 17 , abril- maio/2003, p. 61.

STRECK, L. L. O Senso Comum Teórico e a Violência contra a Mulher: Desvelando a Razão Cínica do Direito em Terra Brasilis. In: Revista de Direito de Família, no 16, jan.- fev.- mar./ 2003, p. 139. 